Research Article

\title{
Characterization and Modelling of LeBlanc Hydrodynamic Stabilizer: A Novel Approach for Steady and Transient State Models
}

\author{
Marlon Wesley Machado Cunico \\ Department of Mechanical Engineering, University of São Paulo, 80320-260 São Carlos, PR, Brazil \\ Correspondence should be addressed to Marlon Wesley Machado Cunico; marloncunico@yahoo.com.br
}

Received 14 October 2014; Revised 12 March 2015; Accepted 14 March 2015

Academic Editor: Aiguo Song

Copyright (C) 2015 Marlon Wesley Machado Cunico. This is an open access article distributed under the Creative Commons Attribution License, which permits unrestricted use, distribution, and reproduction in any medium, provided the original work is properly cited.

\begin{abstract}
As result of increase of customers' demands, products become more complexes and dynamics control increased its role into product development. As example, clothing washing machines use LeBlanc balancers in order to reduce vibration issues. Nevertheless, the behaviour of such apparatus is still hard to describe and the numerical simulation of this sort of vibration control is based on ball rings. The main goal of this work is to define and characterize a numerical model that describes the hydrodynamics balance ring in the transient state in addition to steady state models. As consequence, the behaviour of balance ring was identified in a computational fluid dynamics tool and an equation that describes restoration forces, unbalance, force phase, and eccentricity was found.
\end{abstract}

\section{Introduction}

Along the last years, the demand for high performance appliances has been growing progressively, making the development of vertical axis washing machines be guided by either the increase of capacity, water extraction, washing quality, reduction of vibration or noise. As a consequence of increase of capacity, the gaps between components such as cabinet and tub tend to be decreased, while the increase of basket rotation intends to improve water extraction. Therefore, this combination of factors tends to create more severe application conditions, where the isolator and stabilizer systems are essential to ensure the machine design.

One of the most common stabilizer systems which are possible to be found in vertical axis washing machines is the LeBlanc stabilizer, which is also known as hydrodynamic balance ring, as shown in Figure 1. In this figure, the main elements of a vertical washing machine are also presented, where an unbalance mass represents the unbalance which is caused by clothes during agitation and water extraction $[1,2]$.

This LeBlanc stabilizer consists in the hollow ring which is partially filled by fluid and has the reduction of vibration in the water extraction stage (spinning) as its main purpose. In the spinning stage, it is common that the clothes are implied on unbalance mass, which induce vibration of washing system and generate forces in the basket. Among the main consequences of this condition, we can highlight the contact between basket and tub, the contact between tub and cabinet, and the excessive vibration of machine, which can even result in walking machine [1-8].

In spite of the high volume of researches related to balance ring and washing machine dynamics, most of the models which are found in these studies ignore the transient response and still have several challenges to be overcome. In addition, the computational implementation of these models in dynamic system is very difficult and hardly results in a confident transient response [4]. As alternative to such complexity, the balance ring model which is the most used in dynamic studies consists in distribution of balls inside a ring where the friction provides dampening of ball motion $[2-6,8]$.

For that reason, the main goal of this work is to propose a novel model of balance ring which considers either steady or transient state, being easily implemented in a computational 


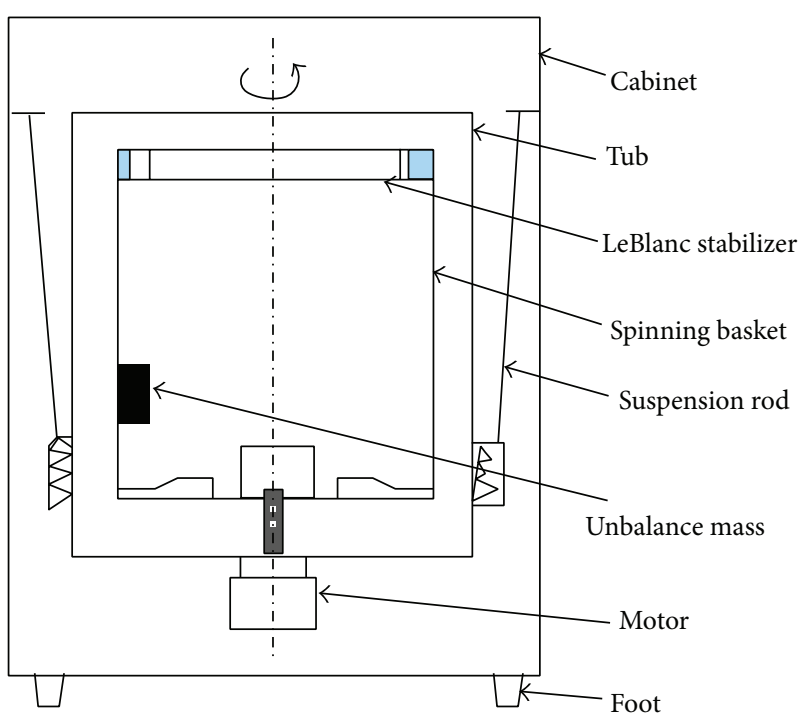

FIGURE 1: Schematic of a vertical axis washing machine and their main components.

dynamical system. In addition, the model was implemented in dynamic system in the plane, evidencing the benefits of balance ring to the washing machine. To achieve this purpose, this work was divided into 3 parts, steady state, transient state, and dynamical system implementation.

For the steady state study, we applied response surface method to identify the behaviour of balance ring as a function of eccentricity, orbit direction, and rotation rate. The responses of this study are balance ring force (restoration or counterbalance force) and water distribution (unbalance water mass inside chamber).

Another point in this study is the decomposing of eccentricity, orbit direction, and rotation in the translational and rotational movement increment along the time. Therefore, it allows us to identify the instantaneous restoration force and force angle phase with respect to unbalance load.

For the transient analysis, we submitted the balance ring to 4 different change states levels at the same rotation, analysing the behaviour of restoration force and water distribution between these states. In this way, a transition equation which defines the behaviour of balance ring in either steady or transient states was identified.

At the end, we applied this model in a simplified dynamical model in order to identify the contribution of balance ring to the dynamics and main efforts of machine.

\section{Material and Methods}

For the steady state study, we applied a response surface with 3 variables and 5 levels. Where eccentricity, orbit orientation, and rotation speed are the control factors and restoration force, restoration force angle and water distribution are the responses. These responses were acquired through a computational fluid dynamics (CFD) analysis, where a multiphase method has been used to model the behaviour of fluid inside the ring chamber.
TABLE 1: Response surface design matrix.

\begin{tabular}{lccccc}
\hline \multirow{2}{*}{ Variables } & \multicolumn{5}{c}{ Control factor levels } \\
& -2 & -1 & 0 & +1 & +2 \\
\hline Eccentricity $(\mathrm{mm})$ & 1 & 4,5 & 8 & 11,5 & 15 \\
Rotation speed $(\mathrm{rpm})$ & 50 & 225 & 400 & 575 & 750 \\
Orbit orientation & $0^{\circ}$ & & $45^{\circ}$ & & 90 \\
\hline
\end{tabular}
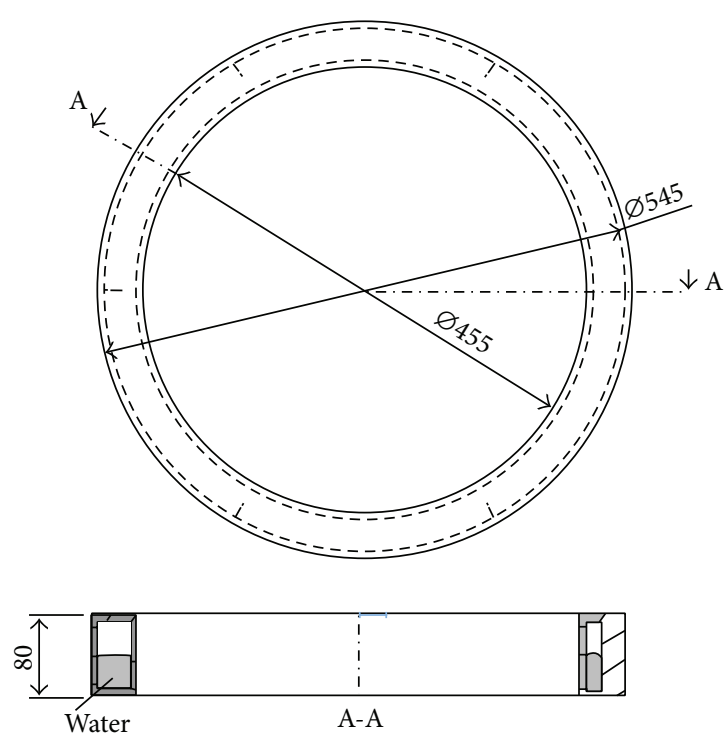

FIGURE 2: Schematic of simplified LeBlanc stabilizer.

For this study, we also considered the LeBlanc stabilizer with $50 \%$ of internal volume filled with water and its geometry are constants. At this point, the main geometrical characteristics of this ring are $455 \mathrm{~mm}$ of inner diameter; $545 \mathrm{~mm}$ of outer diameter; $80 \mathrm{~mm}$ of height; and 6 thins with $80 \mathrm{~mm}$ of height and $20 \mathrm{~mm}$ of length. A schematic of this geometry can be seen in Figure 2.

In Table 1, it is possible to see the study design matrix, where the values variables in each one of their 5 levels are presented. The eccentricity values vary from 1 to $15 \mathrm{~mm}$, rotation speed varies from 50 to $850 \mathrm{rpm}$, and orbit orientation varies from 0 to $90^{\circ}$.

For the simulation model, we defined the average mesh size equal to $0.1 \mathrm{~mm}$ and 8 prism exponential layers. For the transient multiphase domain, we applied volume of fluid (VOF) method where air and water were the fluids phases. We also used for the transient state study a time step equal to 0.00001 seconds and an error of $10^{-8}$ per interaction. In addition, the CFD software that was used to simulate this experimental study was STAR CCM+.

With respect to the orbit orientation, it refers to the way the eccentricity is promoted. For analysing this situation, we assumed that the balance ring has a local and movable coordinate system which is placed in the centre of the ring. As a consequence, we defined the eccentricity and orbit orientation through the combination of rotation and translation motion as presented in (4) and (5). 
TABLE 2: Design matrix of level change.

\begin{tabular}{lcccc}
\hline Eccentricity 1 & Eccentricity 2 & Change level & Time (s) & Transient equation \\
\hline $10 \mathrm{~mm}$ & 1 & $-9 \mathrm{~mm}$ & 1,5 & $F=400-\left(300-300 \cdot e^{-3 \cdot t}\right)$ \\
$10 \mathrm{~mm}$ & $5 \mathrm{~mm}$ & $-5 \mathrm{~mm}$ & 1,5 & $F=400-\left(150-150 \cdot e^{-3 \cdot t}\right)$ \\
$1 \mathrm{~mm}$ & $10 \mathrm{~mm}$ & $9 \mathrm{~mm}$ & 1,5 & $F=100+\left(300-300 \cdot e^{-3 \cdot t}\right)$ \\
$5 \mathrm{~mm}$ & $10 \mathrm{~mm}$ & $4 \mathrm{~mm}$ & 1,5 & $F=250+\left(150-150 \cdot e^{-3 \cdot t}\right)$ \\
\hline
\end{tabular}

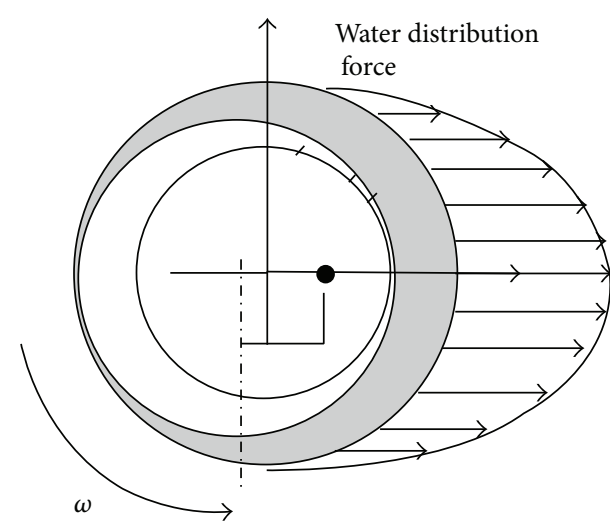

(a)

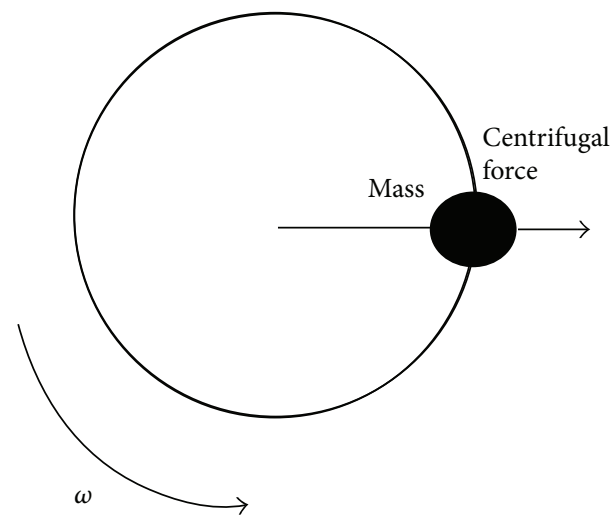

(b)

FIGURE 3: Schematic of restoration force simplification from distributed water force (a) and single mass centrifugal force (b).

For analysis of study responses, we included a reference unbalance load which is useful to determine the phase angle between restoration and unbalance forces. It was also assumed that the restoration force might be represented by just a single mass centrifugal force, simplifying the force which resulted from water distribution, as presented in Figure 3.

For the transient analysis, we analysed the behaviour of restoration force, restoration force angle, and time needed to change between states, as shown in Figure 4. In this figure, it is possible to see the change of states level, such as the transition area, 3 types of transition behaviour, and the definition of each state.

In this case, we selected 4 changes of states levels where the eccentricity varied from 10 to $1 \mathrm{~mm}, 10$ to $5 \mathrm{~mm}, 1$ to $10 \mathrm{~mm}$, and 5 to $10 \mathrm{~mm}$. In Table 2 a matrix with values of eccentricity that define the states and the change of states level is presented. In addition, this table also shows the value of transient time $\left(t_{1}-t_{0}\right)$ and a fitted curve equation which might define the transient state as a function of time.

At the end, we built a rigid body model with 3 degrees of freedom which concerns the proposal balance ring model, the spring stiffness, and viscous damping (friction) in $x$ and $y$. In addition, the washing group mass and unbalance force are also considered in this model. In Figure 5, it is possible to see a schematic of this model, where an unbalance load provides an excitation to the system which is initially stopped. In addition, this figure also presents the main parameters of this system, such as stiffness, friction, mass, and unbalance load.

In order to analyse the influence of LeBlanc stabilizer on this system in different conditions, we forced 3 specific

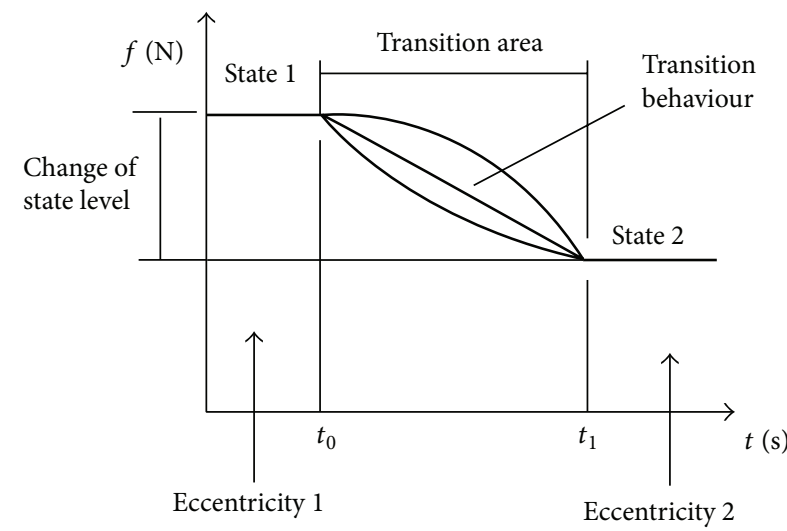

FIGURE 4: Schematic of transition between states.

rotation speed ramps $(15,20$, and $25 \mathrm{rpm} / \mathrm{s})$, as shown in Figure 6. As a result, we analyzed the force of ring, force of unbalance load, and generated orbit. It is important to note that these rotational speed ramps were selected in order to identify the effect of acceleration in LeBlanc stabilizers. In addition, as these values are commonly used in washing machines, the results of this work might be directly applied to optimize such machines.

\section{Results and Discussions}

In the steady state study, it was possible to identify the variation of ring force, the simplified mass distribution, and angle phase between unbalance load (reference) and restoration force. The results that were acquired from CFD 


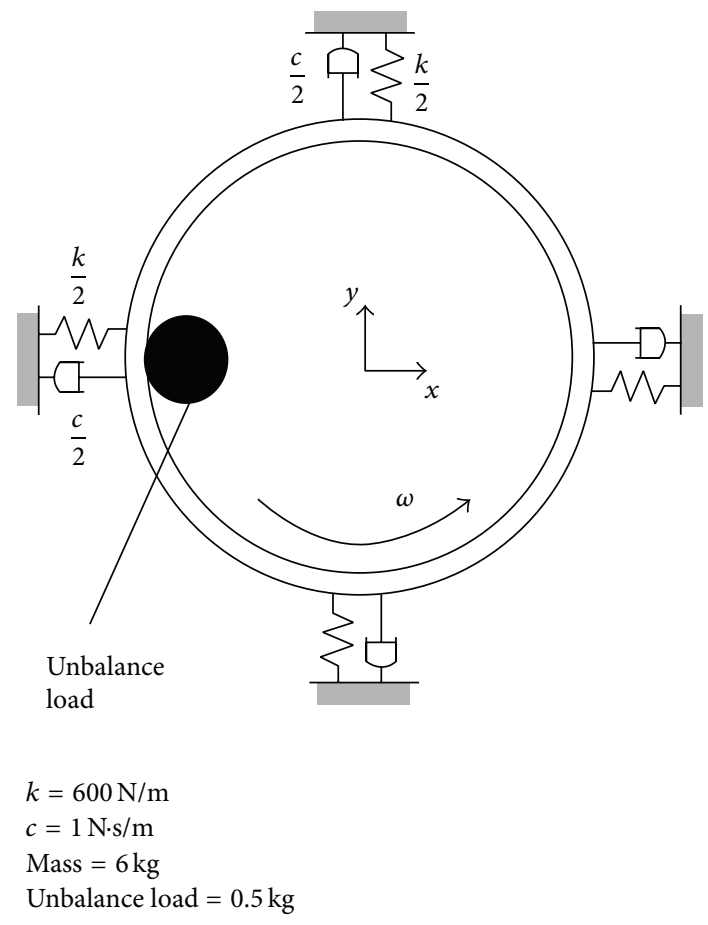

FIGURE 5: Schematic of 3 degrees of freedom (DoF) model.

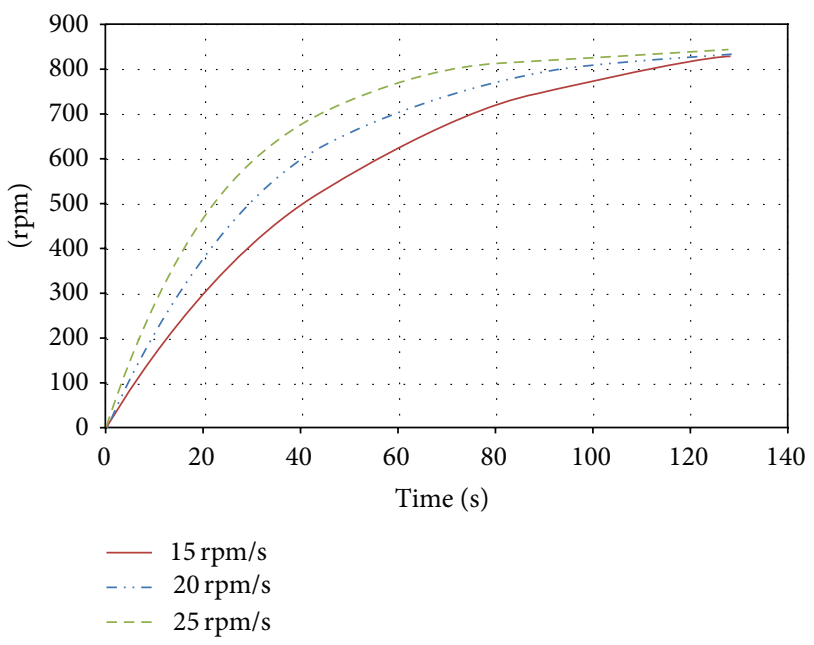

Figure 6: Diagram of rotation speed ramps.

analysis were presented in Table 3, where either the control factors or the response factors are presented.

In Table 3, a reference unbalance load force which results from $0.3 \mathrm{~kg}$ of unbalance can also be seen. Through this reference, it is possible to identify the effectiveness of balance ring restoration force, whereas the equilibrium between these forces might indicate the steady state orbit of system. For example, if the orbit orientation was $180^{\circ}$, the rotation was $400 \mathrm{rpm}$, and the unbalance load was $0.3 \mathrm{~kg}$, the restoration force that would be needed to balance the system is $105 \mathrm{~N}$. Therefore, the orbit that induces this restoration force into balance ring would be $4 \mathrm{~mm}$.
We can also identify that the ring restoration force varies with either the rotation or eccentricity, even though the restoration water mass is more affected by the eccentricity.

In addition, Figure 7 presents the response surface of restoration force $(\mathrm{N})$ as a function of rotation speed (rpm) and eccentricity $(\mathrm{mm})$.

As a result of this study, it was possible to identify a steady state equation for the balance ring restoration mass and force which is based on rotation speed and orbit. This model might be described in

$$
\begin{aligned}
& m=0.0072 \cdot e \cdot(n)^{0.35} \\
& \mathrm{Fr}=0.0072 \cdot e \cdot(n)^{0.35} \cdot\left(\frac{n \cdot 2 \cdot \pi}{60}\right)^{2} \cdot r
\end{aligned}
$$

where $m$ is the restoration mass $(\mathrm{kg}), e$ is the eccentricity $(\mathrm{mm}), n$ is the rotation speed (rpm), Fr is the restoration force of ring $(\mathrm{N})$, and $r$ is the ring radius $(\mathrm{m})$.

In this table, we can also identify that the absolute ring force might not be affected by the orbit orientation, even though the translational component of motion results in different water distribution. In Figure 8, an illustration of balance ring water distribution that resulted from rotation of $500 \mathrm{rpm}, 10 \mathrm{~mm}$ of eccentricity, and orbit orientation equal to $90^{\circ}$ (a) and $180^{\circ}$ (b) is presented.

In order to model the behaviour of balance ring in a computational way, we assumed that the balance ring has a local and movable coordinate system which is placed in the centre of the ring. As a consequence, the position of the local coordinate system at s-ésim time increment can be defined by

$$
\begin{aligned}
H_{\text {local }}(e)= & {\left[\begin{array}{ccc}
\cos \left(\theta_{\text {global }}\right) & \sin \left(\theta_{\text {global }}\right) & x_{\text {global }} \\
-\sin \left(\theta_{\text {global }}\right) & \cos \left(\theta_{\text {global }}\right) & y_{\text {global }} \\
0 & 0 & 1
\end{array}\right] } \\
& \cdot\left[\begin{array}{ccc}
\cos (d \theta) & \sin (d \theta) & d x \\
-\sin (d \theta) & \cos (d \theta) & d y \\
0 & 0 & 1
\end{array}\right]^{n},
\end{aligned}
$$

where $H_{\text {local }}$ is the position matrix of movable coordinate system in s-ésim time increment, $s$ is the e-ésim time increment, $x_{\text {global }}$ and $y_{\text {global }}$ are the absolute distance between the centre ring and a fixed global coordinate system [m], $\theta_{\text {global }}$ is the absolute angle between the movable coordinate $x$-axis (ring) and a fix global coordinate system [rad], $d x$ and $d y$ are the decrement of movable coordinates in s-ésim time increment [m], and $d \theta$ is the decrement of angle in s-ésim time increment [rad].

At the same way, the rotation speed might be defined as

$$
\omega=\frac{n}{60} \cdot 2 \cdot \pi=\frac{d \theta}{d t}=\frac{d}{d t}\left[\begin{array}{ccc}
\cos (d \theta) & \sin (d \theta) & 0 \\
-\sin (d \theta) & \cos (d \theta) & 0 \\
0 & 0 & 1
\end{array}\right] \text {, }
$$

where $\omega$ is the angular velocity $[\mathrm{rad} / \mathrm{s}], n$ is the rotation speed [rpm], and $d \theta$ is the decrement of angle in an instant of time $(d t)$ [rad]. 
TABLE 3: Results of steady state study.

\begin{tabular}{|c|c|c|c|c|c|c|}
\hline \multicolumn{3}{|c|}{ Control factor } & \multicolumn{4}{|c|}{ Response factors } \\
\hline $\begin{array}{l}\text { Rotation } \\
(\mathrm{rpm})\end{array}$ & Eccentricity $(\mathrm{mm})$ & $\begin{array}{c}\text { Orbit } \\
\text { orientation }\end{array}$ & $\begin{array}{c}\text { Restoration } \\
\text { force }(\mathrm{N})\end{array}$ & $\begin{array}{c}\text { Restoration } \\
\text { mass }(\mathrm{kg})\end{array}$ & Phase (deg) & $\begin{array}{l}\text { Unbalance } \\
\text { (300 g - ref) }\end{array}$ \\
\hline 50 & 1 & 0 & 0,15 & 0,022 & 180 & 1,65 \\
\hline 50 & 4,5 & 0 & 0,7 & 0,102 & 180 & 1,65 \\
\hline 50 & 8 & 0 & 1,4 & 0,204 & 180 & 1,65 \\
\hline 50 & 11,5 & 0 & 2 & 0,292 & 180 & 1,65 \\
\hline 50 & 15 & 0 & 2,65 & 0,387 & 180 & 1,65 \\
\hline 225 & 1 & 0 & 6,5 & 0,047 & 180 & 33 \\
\hline 225 & 4,5 & 0 & 37 & 0,267 & 180 & 33 \\
\hline 225 & 8 & 0 & 65 & 0,468 & 180 & 33 \\
\hline 225 & 11,5 & 0 & 85 & 0,612 & 180 & 33 \\
\hline 225 & 15 & 0 & 100 & 0,721 & 180 & 33 \\
\hline 400 & 1 & 0 & 20 & 0,046 & 180 & 105 \\
\hline 400 & 4,5 & 0 & 125 & 0,285 & 180 & 105 \\
\hline 400 & 8 & 0 & 230 & 0,524 & 180 & 105 \\
\hline 400 & 11,5 & 0 & 295 & 0,673 & 180 & 105 \\
\hline 400 & 15 & 0 & 340 & 0,775 & 180 & 105 \\
\hline 575 & 1 & 0 & 50 & 0,055 & 180 & 217 \\
\hline 575 & 4,5 & 0 & 280 & 0,309 & 180 & 217 \\
\hline 575 & 8 & 0 & 480 & 0,530 & 180 & 217 \\
\hline 575 & 11,5 & 0 & 660 & 0,728 & 180 & 217 \\
\hline 575 & 15 & 0 & 800 & 0,883 & 180 & 217 \\
\hline 750 & 1 & 0 & 105 & 0,068 & 180 & 370 \\
\hline 750 & 4,5 & 0 & 500 & 0,324 & 180 & 370 \\
\hline 750 & 8 & 0 & 1000 & 0,648 & 180 & 370 \\
\hline 750 & 11,5 & 0 & 1300 & 0,843 & 180 & 370 \\
\hline 750 & 15 & 0 & 1530 & 0,992 & 180 & 370 \\
\hline 50 & 1 & 45 & 0,15 & 0,022 & 45 & 1,65 \\
\hline 50 & 4,5 & 45 & 0,7 & 0,102 & 45 & 1,65 \\
\hline 50 & 8 & 45 & 1,4 & 0,204 & 45 & 1,65 \\
\hline 50 & 11,5 & 45 & 2 & 0,292 & 45 & 1,65 \\
\hline 50 & 15 & 45 & 2,65 & 0,387 & 45 & 1,65 \\
\hline 225 & 1 & 45 & 6,5 & 0,047 & 45 & 33 \\
\hline 225 & 4,5 & 45 & 37 & 0,267 & 45 & 33 \\
\hline 225 & 8 & 45 & 65 & 0,468 & 45 & 33 \\
\hline 225 & 11,5 & 45 & 85 & 0,612 & 45 & 33 \\
\hline 225 & 15 & 45 & 100 & 0,721 & 45 & 33 \\
\hline 400 & 1 & 45 & 20 & 0,046 & 45 & 105 \\
\hline 400 & 4,5 & 45 & 125 & 0,285 & 45 & 105 \\
\hline 400 & 8 & 45 & 230 & 0,524 & 45 & 105 \\
\hline 400 & 11,5 & 45 & 295 & 0,673 & 45 & 105 \\
\hline 400 & 15 & 45 & 340 & 0,775 & 45 & 105 \\
\hline 575 & 1 & 45 & 50 & 0,055 & 45 & 217 \\
\hline 575 & 4,5 & 45 & 280 & 0,309 & 45 & 217 \\
\hline 575 & 8 & 45 & 480 & 0,530 & 45 & 217 \\
\hline 575 & 11,5 & 45 & 660 & 0,728 & 45 & 217 \\
\hline 575 & 15 & 45 & 800 & 0,883 & 45 & 217 \\
\hline 750 & 1 & 45 & 105 & 0,068 & 45 & 370 \\
\hline 750 & 4,5 & 45 & 500 & 0,324 & 45 & 370 \\
\hline 750 & 8 & 45 & 1000 & 0,648 & 45 & 370 \\
\hline 750 & 11,5 & 45 & 1300 & 0,843 & 45 & 370 \\
\hline 750 & 15 & 45 & 1530 & 0,992 & 45 & 370 \\
\hline 50 & 1 & 90 & 0,15 & 0,022 & 90 & 1,65 \\
\hline 50 & 4,5 & 90 & 0,7 & 0,102 & 90 & 1,65 \\
\hline
\end{tabular}


TABle 3: Continued.

\begin{tabular}{|c|c|c|c|c|c|c|}
\hline \multicolumn{3}{|c|}{ Control factor } & \multicolumn{4}{|c|}{ Response factors } \\
\hline $\begin{array}{l}\text { Rotation } \\
(\mathrm{rpm})\end{array}$ & Eccentricity (mm) & $\begin{array}{c}\text { Orbit } \\
\text { orientation }\end{array}$ & $\begin{array}{c}\text { Restoration } \\
\text { force }(\mathrm{N})\end{array}$ & $\begin{array}{c}\text { Restoration } \\
\text { mass (kg) }\end{array}$ & Phase (deg) & $\begin{array}{l}\text { Unbalance } \\
(300 \mathrm{~g}-\text { ref })\end{array}$ \\
\hline 50 & 8 & 90 & 1,4 & 0,204 & 90 & 1,65 \\
\hline 50 & 11,5 & 90 & 2 & 0,292 & 90 & 1,65 \\
\hline 50 & 15 & 90 & 2,65 & 0,387 & 90 & 1,65 \\
\hline 225 & 1 & 90 & 6,5 & 0,047 & 90 & 33 \\
\hline 225 & 4,5 & 90 & 37 & 0,267 & 90 & 33 \\
\hline 225 & 8 & 90 & 65 & 0,468 & 90 & 33 \\
\hline 225 & 11,5 & 90 & 85 & 0,612 & 90 & 33 \\
\hline 225 & 15 & 90 & 100 & 0,721 & 90 & 33 \\
\hline 400 & 1 & 90 & 20 & 0,046 & 90 & 105 \\
\hline 400 & 4,5 & 90 & 125 & 0,285 & 90 & 105 \\
\hline 400 & 8 & 90 & 230 & 0,524 & 90 & 105 \\
\hline 400 & 11,5 & 90 & 295 & 0,673 & 90 & 105 \\
\hline 400 & 15 & 90 & 340 & 0,775 & 90 & 105 \\
\hline 575 & 1 & 90 & 50 & 0,055 & 90 & 217 \\
\hline 575 & 4,5 & 90 & 280 & 0,309 & 90 & 217 \\
\hline 575 & 8 & 90 & 480 & 0,530 & 90 & 217 \\
\hline 575 & 11,5 & 90 & 660 & 0,728 & 90 & 217 \\
\hline 575 & 15 & 90 & 800 & 0,883 & 90 & 217 \\
\hline 750 & 1 & 90 & 105 & 0,068 & 90 & 370 \\
\hline 750 & 4,5 & 90 & 500 & 0,324 & 90 & 370 \\
\hline 750 & 8 & 90 & 1000 & 0,648 & 90 & 370 \\
\hline 750 & 11,5 & 90 & 1300 & 0,843 & 90 & 370 \\
\hline 750 & 15 & 90 & 1530 & 0,992 & 90 & 370 \\
\hline
\end{tabular}
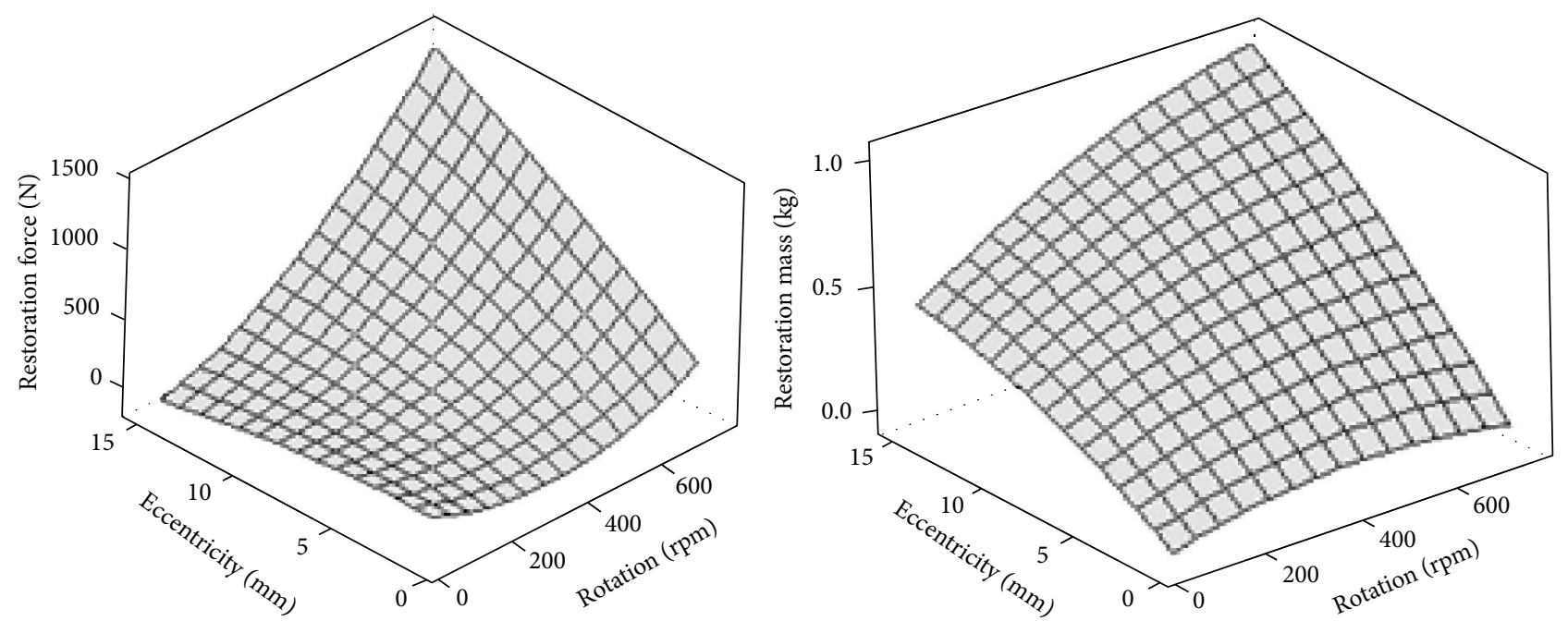

FIGURE 7: Response surface of steady state study correlating rotation speed (rpm), eccentricity (mm), restoration force (N), and restoration mass (kg). 


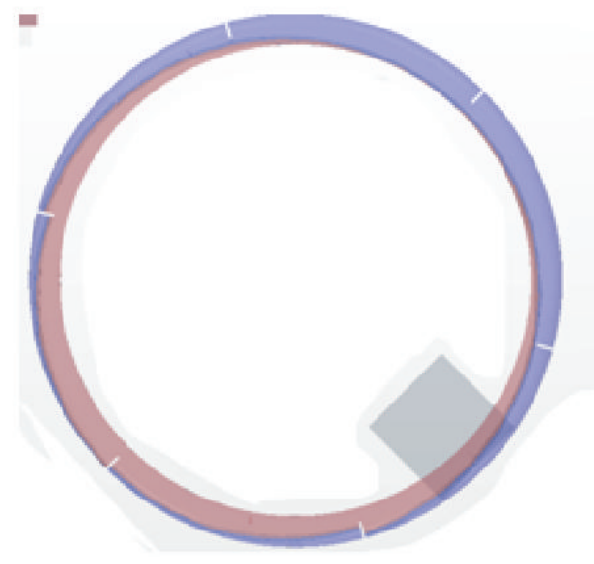

(a)

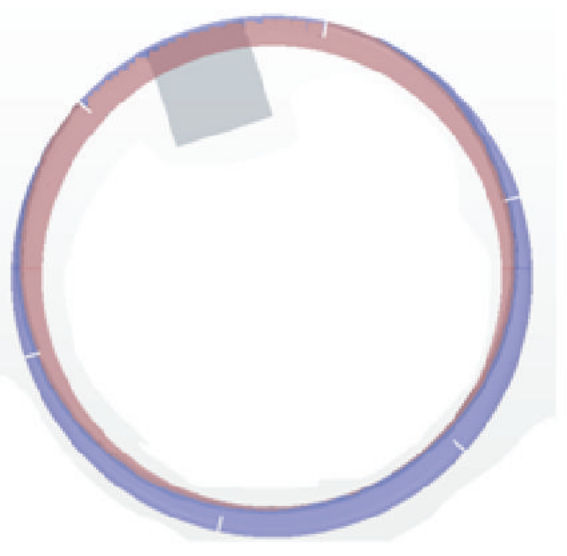

(b)

FIGURE 8: Representation of balance ring water distribution for $10 \mathrm{~mm}$ eccentricity and $500 \mathrm{rpm}$ rotation, where (a) is $90^{\circ}$ phase angle and (b) is $180^{\circ}$ phase angle.

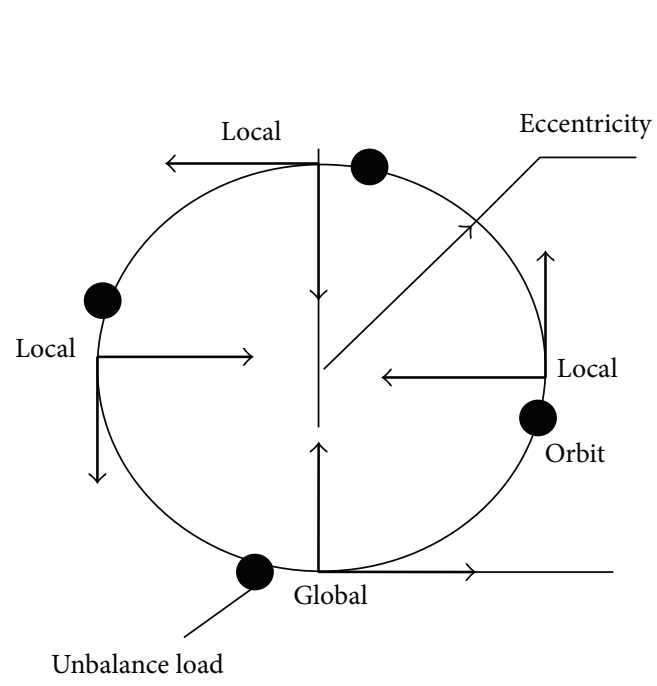

(a)

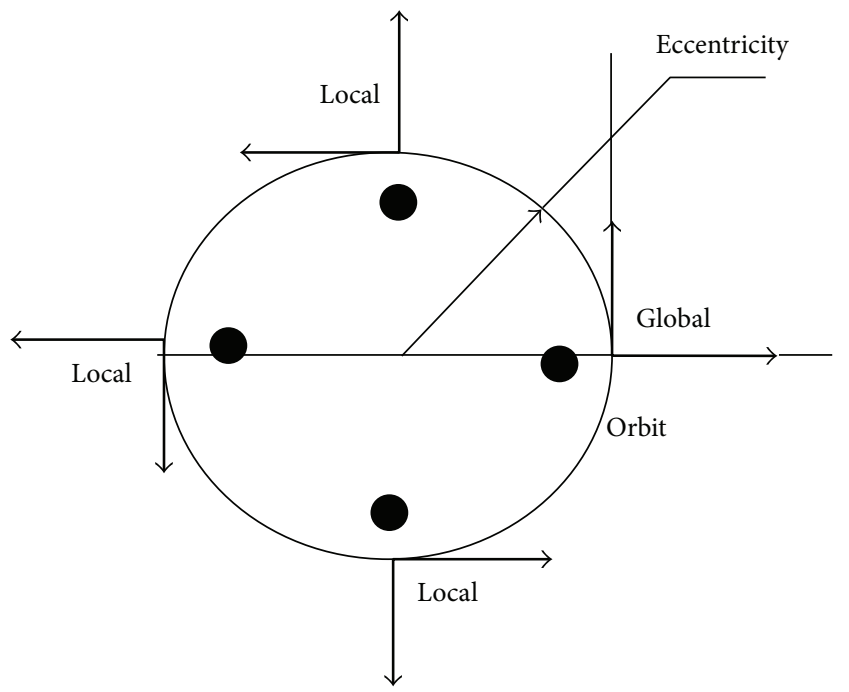

(b)

FIGURE 9: Schematic of orbit orientation for motion component: (a) angular velocity $(\omega)$, translational velocity in $x$-axis $\left(v_{x}\right)$ and (b) angular velocity $(\omega)$, translational velocity in $y$-axis $\left(v_{y}\right)$.

And, in consequence, the combination of translation and a constant rotation causes a defined eccentricity:

$$
e=\frac{\sqrt{(d x / 2)^{2}+(d y / 2)^{2}}}{\sin (d \theta / 2)} .
$$

Moreover, in spite of eccentricity, it is also possible to determine the orientation of movement with respect to the global coordinate and unbalance load, as presented in Figure 9.

It can be noted that each orbit orientation results in a different angle between the unbalance load which follows the local coordinate and the radial eccentricity vector.
Therefore, we can define this orbit orientation angle $(\alpha)$ through

$$
\alpha=a \cos \left(\frac{(d x / 2)}{\sqrt{(d x / 2)^{2}+(d y / 2)^{2}}}\right) .
$$

As a consequence, if we replace (3) and (4) into (1), we could find the absolute values of restoration mass $(m)$ and restoration force $(\mathrm{Fr})$ :

$$
\begin{aligned}
m= & 0.0072 \cdot\left(\frac{\sqrt{(d x / 2)^{2}+(d y / 2)^{2}}}{\sin (d \theta / 2)}\right) \\
& \cdot\left(\frac{d \theta}{d t} \cdot \frac{60}{2 \cdot \pi}\right)^{0.35},
\end{aligned}
$$




$$
\begin{gathered}
\mathrm{Fr}=0.0072 \cdot\left(\frac{\sqrt{(d x / 2)^{2}+(d y / 2)^{2}}}{\sin (d \theta / 2)}\right) \\
\cdot\left(\frac{d \theta}{d t} \cdot \frac{60}{2 \cdot \pi}\right)^{0.35} \cdot\left(\frac{d \theta}{d t}\right)^{2} \cdot r .
\end{gathered}
$$

With respect to the transient study, it was possible to identify the transient equation for each change of state level, as presented in Table 2. In this table, it is possible to identify either transition time between steady states or transient equations. It is also important to highlight that these equations result from the same model, having just a small divergence in the coefficients values.

In spite of that, it might be noted that this transient equation is a function of time and, consequently, implied on a computational implementation in discrete time very hard. Therefore, we converted this equation from the time domain to the decrement of time domain in order to allow for doing the convolution operation.

The result of this conversion can be seen in (7) where the transient equation in time domain and decrement of time domain are presented, where $m$ is the restoration mass as a function of time, $m_{c}$ is the steady state restoration mass, and $c$ is the transitional coefficient. In this equation, $d \tau$ is the increment of time or time step:

$$
m_{(t)}=\int_{0}^{t}\left(m_{c(t)}-m_{c(t-\tau)}\right) \cdot c \cdot d \tau=\left(m_{c}-m_{c} \cdot e^{-c \cdot t}\right) .
$$

In addition, we can identify the increment of restoration mass at each instant of time according to (8), where $d m$ is the increment restoration mass:

$$
d m_{(t)}=\left(m_{c(t)}-m_{c(t-\tau)}\right) \cdot c \cdot d \tau .
$$

Therefore, if we replace (6) into (7) we can find the transient model of LeBlanc stabilizer, where $a$ is the angular model coefficient and $\delta$ is an exponential model coefficient:

$$
\begin{aligned}
& m_{(t)}=m_{c(t-\tau)}+\left(a \cdot \frac { \sqrt { ( d x / 2 ) ^ { 2 } + ( d y / 2 ) ^ { 2 } } } { \operatorname { s i n } ( d \theta / 2 ) } \cdot \left(\frac{60}{2 \cdot \pi}\right.\right. \\
& \left.\left.\cdot \frac{d \theta}{d \tau}\right)^{\delta}-m_{c(t-\tau)}\right) \cdot c \cdot d \tau, \\
& \operatorname{Fr}=\left(m_{c(t-\tau)}+\left(a \cdot \frac{\sqrt{(d x / 2)^{2}+(d y / 2)^{2}}}{\sin (d \theta / 2)}\right.\right. \\
& \left.\left..\left(\frac{60}{2 \cdot \pi} \cdot \frac{d \theta}{d \tau}\right)^{\delta}-m_{c(t-\tau)}\right) \cdot c \cdot d \tau\right) \cdot\left(\frac{d \theta}{d t}\right)^{2} \\
& \quad r .
\end{aligned}
$$

Therefore, this model might indicate the instantaneous values of restoration force (Fr), equivalent unbalance mass $(m)$, and phase angle between unbalance load and restoration force as a function of ring translational decrement $(d x, d y)$ and ring angular decrement $(d \theta)$.

At the end, we applied this numerical model into a rigid body model with 3 degrees of freedom (DoF), identifying the force of unbalance load, restoration force, orbit, and phase angle between unbalance load and restoration force.

In Figure 10, the results of dynamic system with no balance ring analyses are presented, where the diagrams of orbit displacement and unbalance load represent the main responses of this study.

In this figure, it is possible to see that, at the final stage, the orbits tend to increase as a function of rotation acceleration, while the initial stages of analyses are marked by a pick of orbit, which might be related to the natural frequency of system. In either cases, we can also identify that unbalance load is implied on a force between 950 and $1000 \mathrm{~N}$, resulting in additional stress and deflection of mechanical components, such as basket, hub, and shaft. For example, if we considered that the basket height is $500 \mathrm{~mm}$ and the unbalance load is placed at the middle height, the moment at the tip of motor shaft would be approximately $250 \mathrm{~N} \cdot \mathrm{m}$. Moreover, this effort might be implied on excessive deflection of basket (interference between tub and basket) or even the collapse of system.

On the other hand, Figure 11 shows the dynamic systems analyses which considered balance ring. It is possible to see that the balance ring causes a reduction of orbit at intermediate and final stages, even though the initial stages still present the pick of orbit which is related to natural frequency. Otherwise, for that configuration of dynamic system, the values of orbit eccentricity have been shown to be reduced from 10 to $6 \mathrm{~mm}$, indicating a tremendous improvement from the vibration perspective.

In spite of that, it is important to note that the balance ring resulted in forces from 750 to $850 \mathrm{~N}$ at the final stages. Therefore, if we considered basket with height equal to $500 \mathrm{~m}$, the unbalance load at the middle height and the balance ring that the top of basket, the resulting moment at the tip of motor shaft would be $125 \mathrm{~N} \cdot \mathrm{m}$. That moment decreasing $(125 \mathrm{~N} \cdot \mathrm{m})$ might result, for example, in the decrease of shaft diameter and consequently the decrease of cost. On the other hand, this condition makes also it possible to increase rotation and washing machine capacity.

At the end, it was possible to see that the contribution of LeBlanc stabilizer for the washing machine dynamics is extremely important, whereas it reduces the obit of system in transient state and reduces efforts in structural mechanical components, such as basket and shaft.

\section{Conclusions}

In conclusion, both new steady and transient state models were proposed in this work, being possible to characterize the general behaviour of LeBlanc stabilizer as a function of rotation speed, eccentricity, and orbit orientation. 

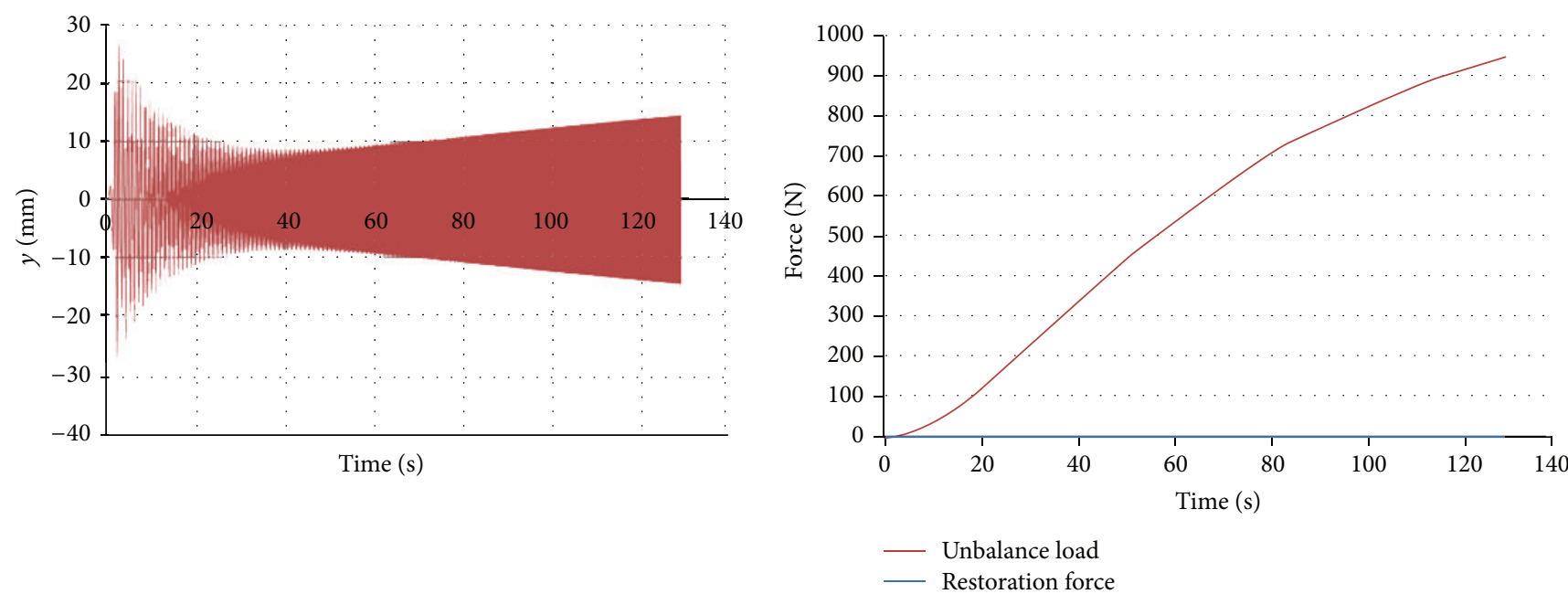

(a)
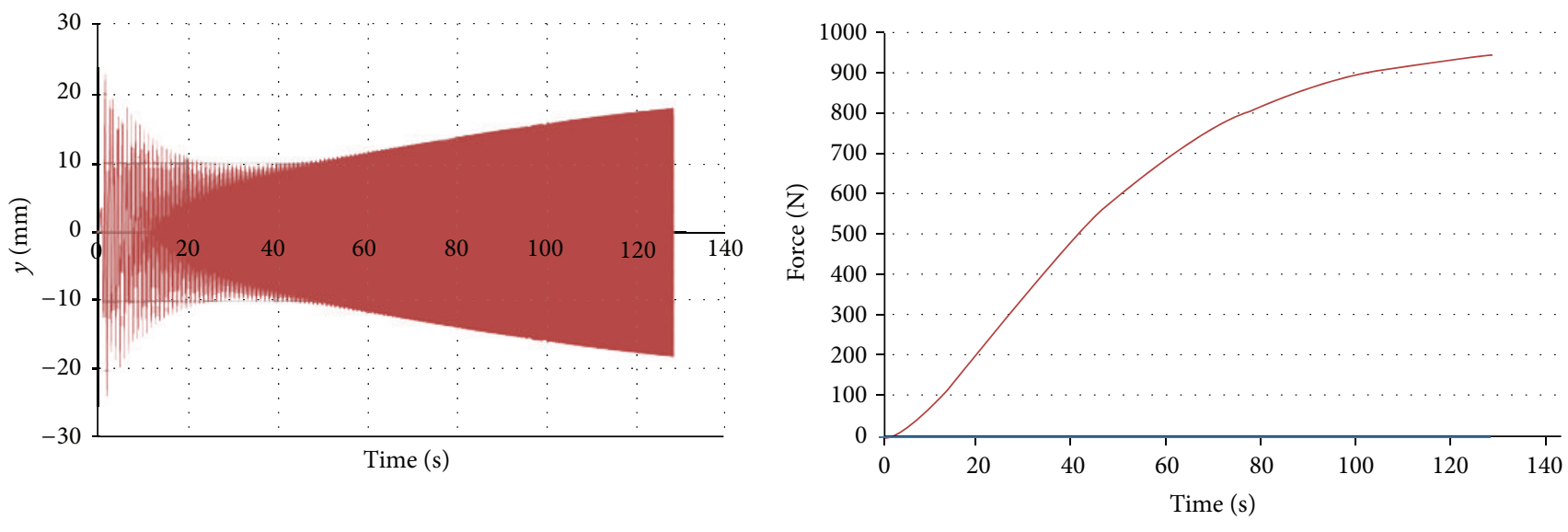

Unbalance load

- Restoration force

(b)
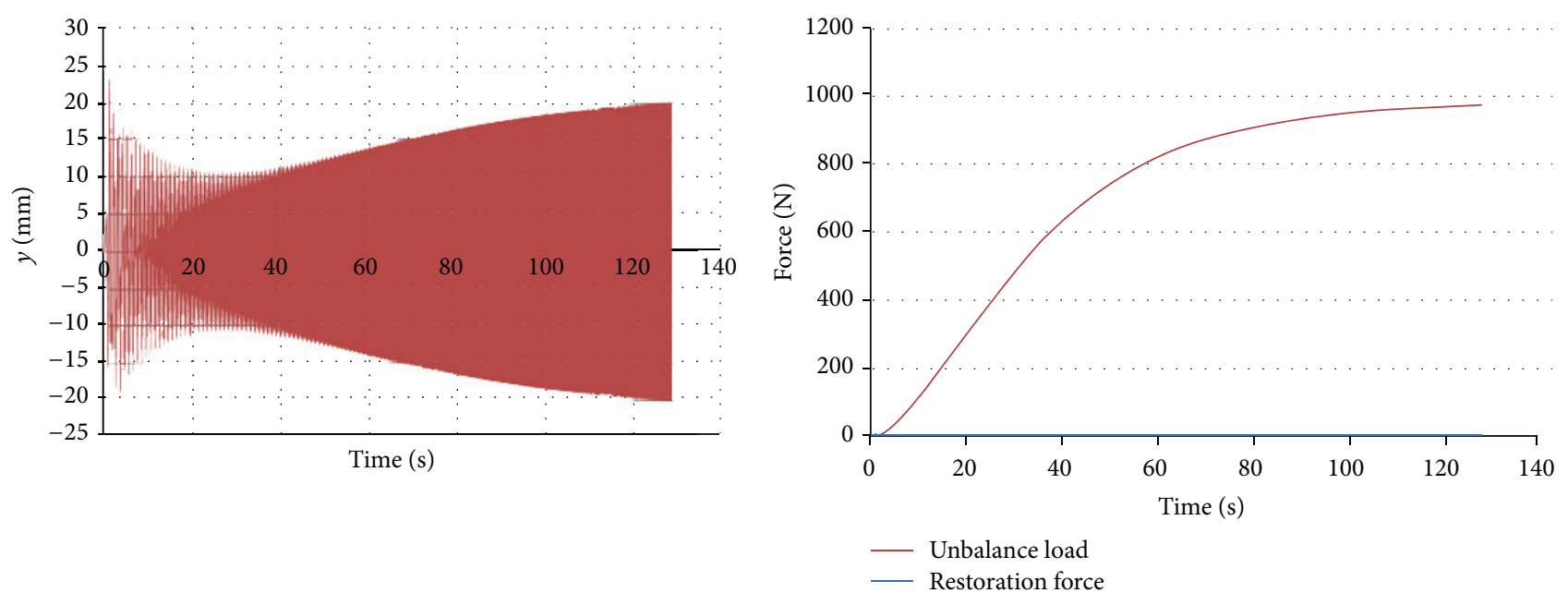

(c)

FIGURE 10: Diagram of orbit displacement ( $y$ direction) and unbalance load for system without balance ring with ramp acceleration equal to (a) $15 \mathrm{rpm} / \mathrm{s}$; (b) $20 \mathrm{rpm} / \mathrm{s}$; and (c) $25 \mathrm{rpm} / \mathrm{s}$. 

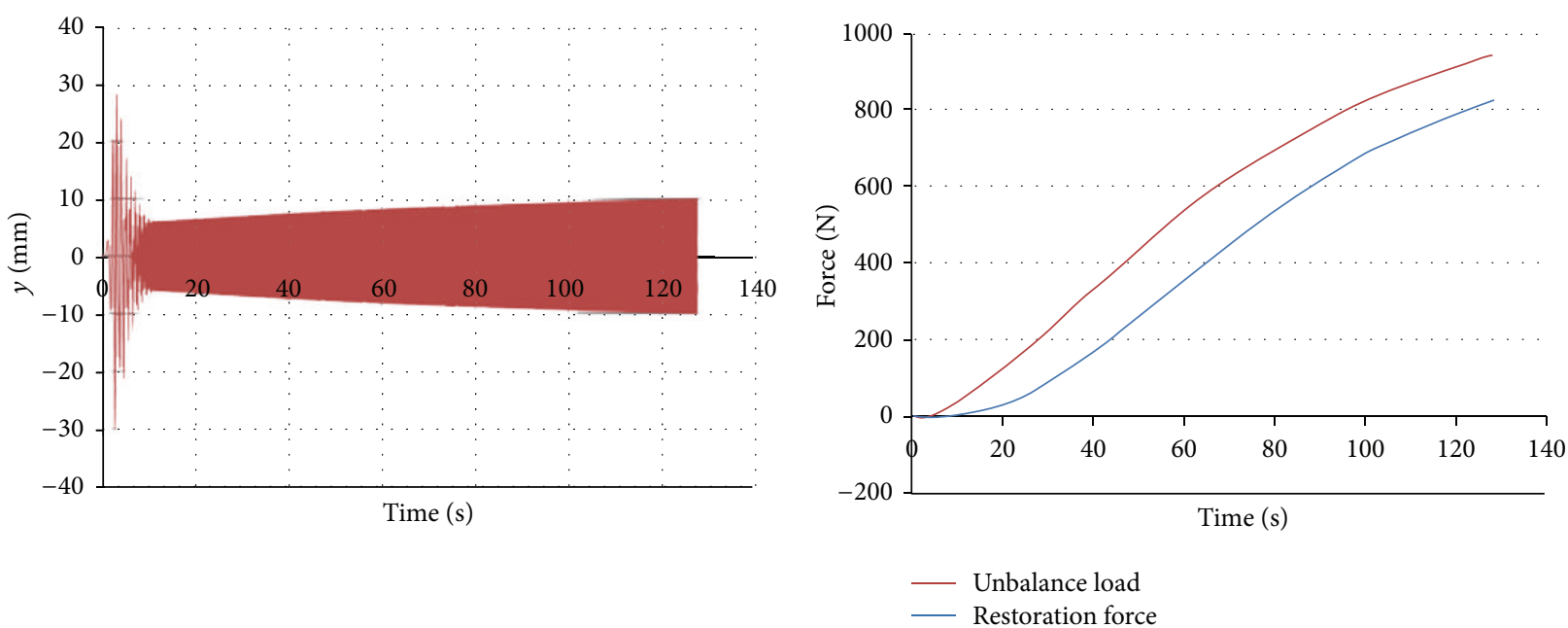

(a)
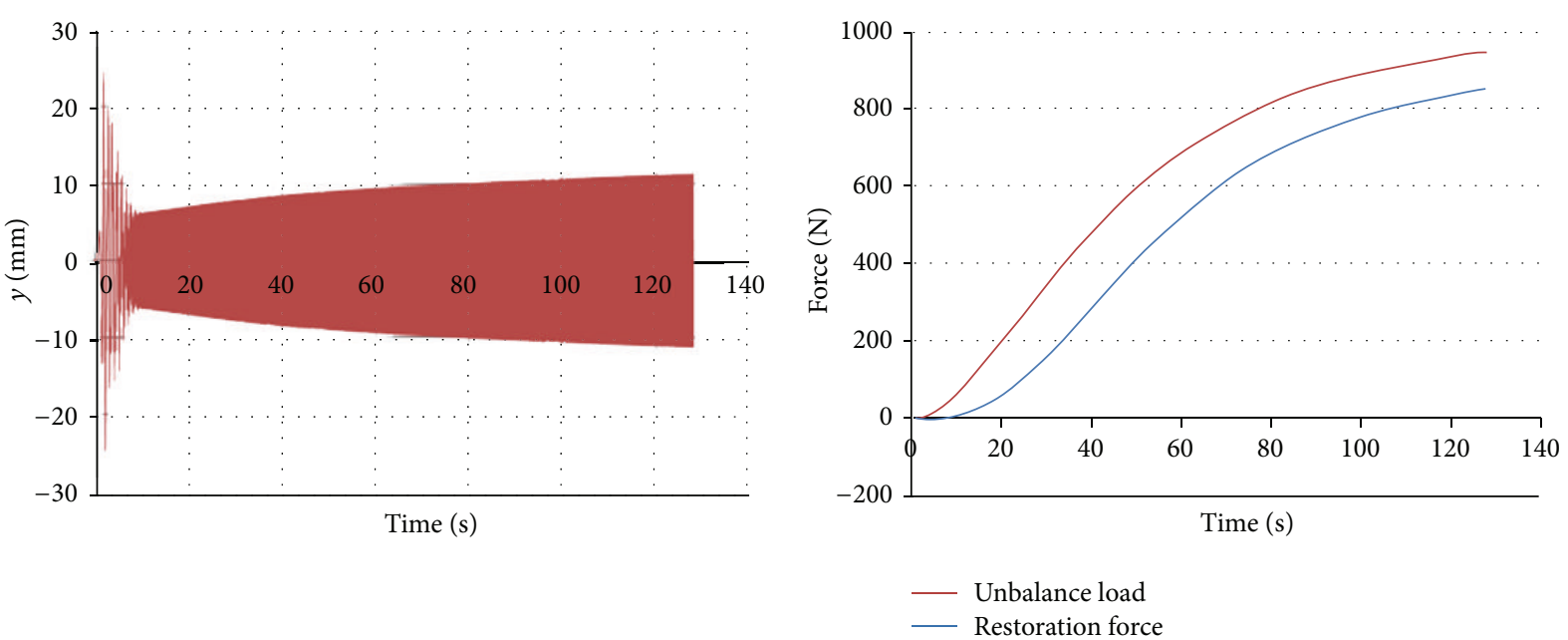

(b)
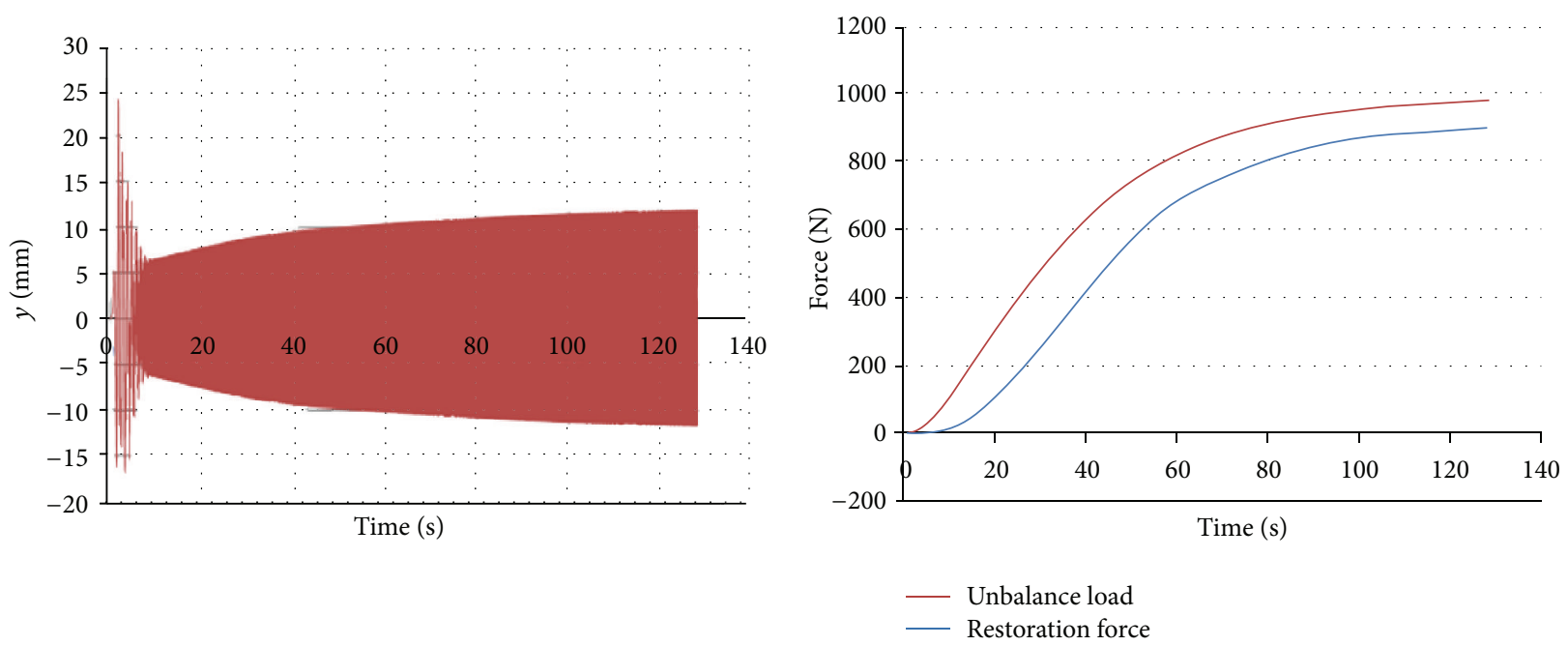

(c)

FiguRE 11: Diagram of orbit displacement ( $y$ direction) and unbalance load for system with balance ring with ramp acceleration equal to (a) $15 \mathrm{rpm} / \mathrm{s}$; (b) $20 \mathrm{rpm} / \mathrm{s}$; and (c) $25 \mathrm{rpm} / \mathrm{s}$. 
In this work, it was also possible to find a simplified equation of restoration mass and force, as well as the phase angle between this force and the reference unbalance load. In addition, a model which is based on 3 degrees of freedom motion was also proposed, where the rotation, eccentricity, and orbit orientation could be described through the rotational and translational increments at time $(d \theta, d x$, and $d y)$.

On the other hand, this work also allows for finding transient equations which are based on time and increment of time domains. Therefore, for the characterization of balance ring, the time domain model helps us to compare efficiency of balance rings in an easy way (transition time between states), while the increment of time model does to implement the model computationally.

As a result of this model, we have been able to build a simplified dynamic model with 3 DOF, where it was possible to identify the general behaviour of a balance ring in a dynamic system besides predicting the response of this system.

On the other hand, it can be helpful to other sorts of analyses, such as the prediction of basket deflection through the difference between unbalance and restoration forces.

Moreover, in spite of the fact that this work still has several challenges to be overcome, this work presented a novel approach for the characterization of LeBlanc stabilizer which make it possible to represent balance rings behaviour in dynamics simulation without computational performance drawbacks.

\section{Conflict of Interests}

The author declares that there is no conflict of interests regarding the publication of this paper.

\section{References}

[1] A.Thompson-Salinas, M. Ortega-Breña, M.H.dela Torre-Ibarra, B. Barrientos-García, and V. J. Gonzalez-Villela, "Hydraulic balance ring study and design using optical techniques," in Proceedings of the ASME International Mechanical Engineering Congress and Exposition, pp. 371-381, Denver, Colo, USA, November 2011.

[2] H. S. Hoon, L. J. Young, S. Suzuki, and H. W. Gu, "A study on the dynamic behaviour of an automatic washing machine," Nippon Kikai Gakkai Kankyo Kogaku Sogo Shinpojiumu Koen Ronbunshu, vol. 11, pp. 131-134, 2001.

[3] H.-W. Chen, W.-X. Ji, Q.-J. Zhang, Y. Cao, and S.-Y. Fan, "A method for vibration isolation of a vertical axis automatic washing machine with a hydraulic balancer," Journal of Mechanical Science and Technology, vol. 26, no. 2, pp. 335-343, 2012.

[4] H.-W. Chen and Q.-J. Zhang, "Stability analyses of a vertical axis automatic washing machine without balancer," Journal of Sound and Vibration, vol. 329, no. 11, pp. 2177-2192, 2010.

[5] H.-W. Chen and Q.-J. Zhang, "Stability analyses of a vertical axis automatic washing machine with a hydraulic balancer," Mechanism and Machine Theory, vol. 46, no. 7, pp. 910-926, 2011.

[6] H.-W. Chen, Q.-J. Zhang, and S.-Y. Fan, "Study on steadystate response of a vertical axis automatic washing machine with a hydraulic balancer using a new approach and a method for getting a smaller deflection angle," Journal of Sound and Vibration, vol. 330, no. 9, pp. 2017-2030, 2011.

[7] C.-H. Jung, C.-S. Kim, and Y.-H. Choi, "A dynamic model and numerical study on the liquid balancer used in an automatic washing machine," Journal of Mechanical Science and Technology, vol. 22, no. 9, pp. 1843-1852, 2008.

[8] V. Royzman and I. Drach, "Improving theory for automatic balancing of rotating rotors with liquid self balancers," Mechanika, vol. 4, no. 54, pp. 38-43, 2005. 

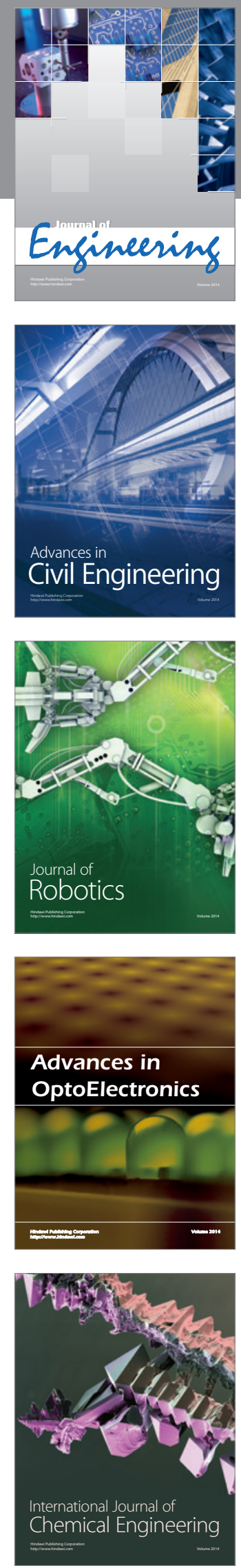

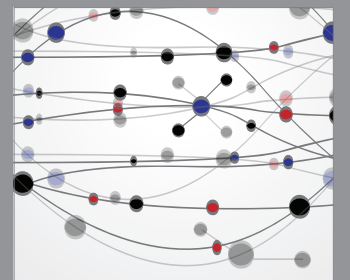

The Scientific World Journal
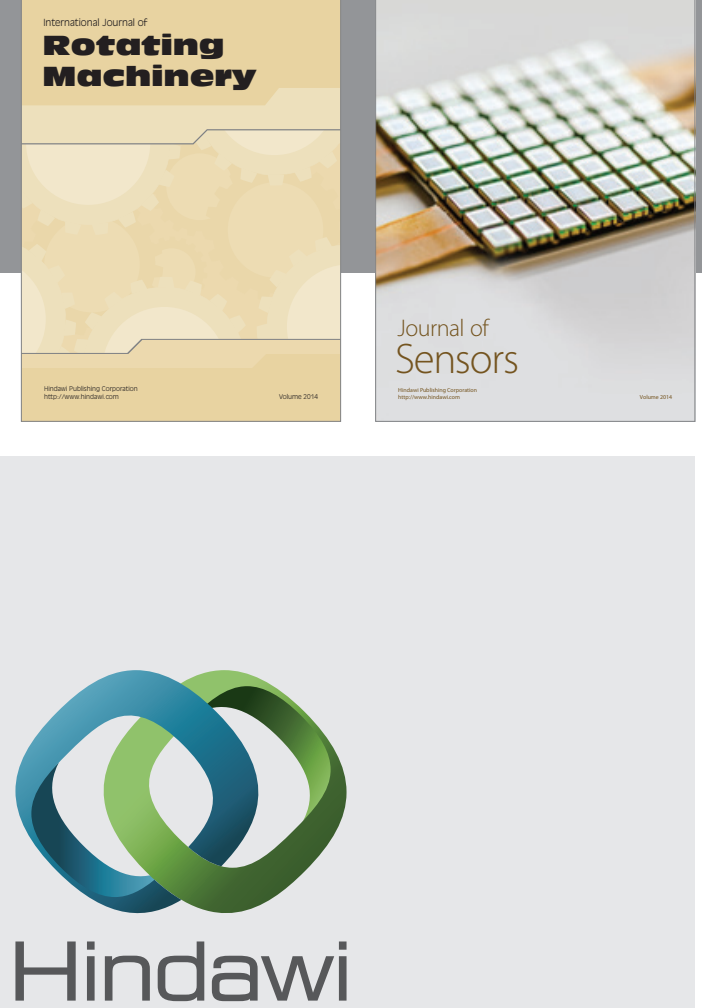

Submit your manuscripts at http://www.hindawi.com
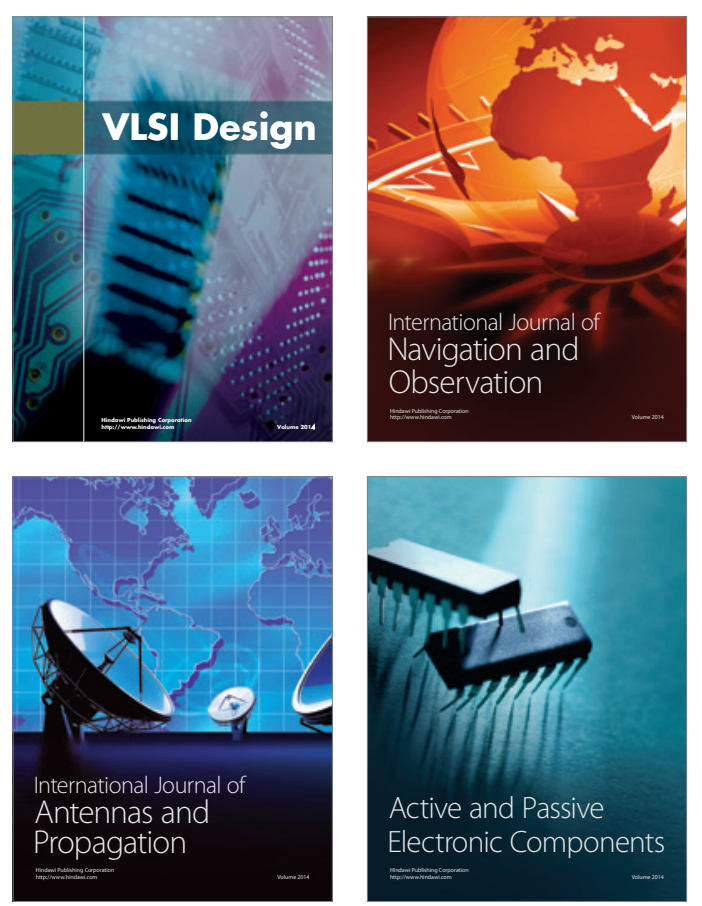
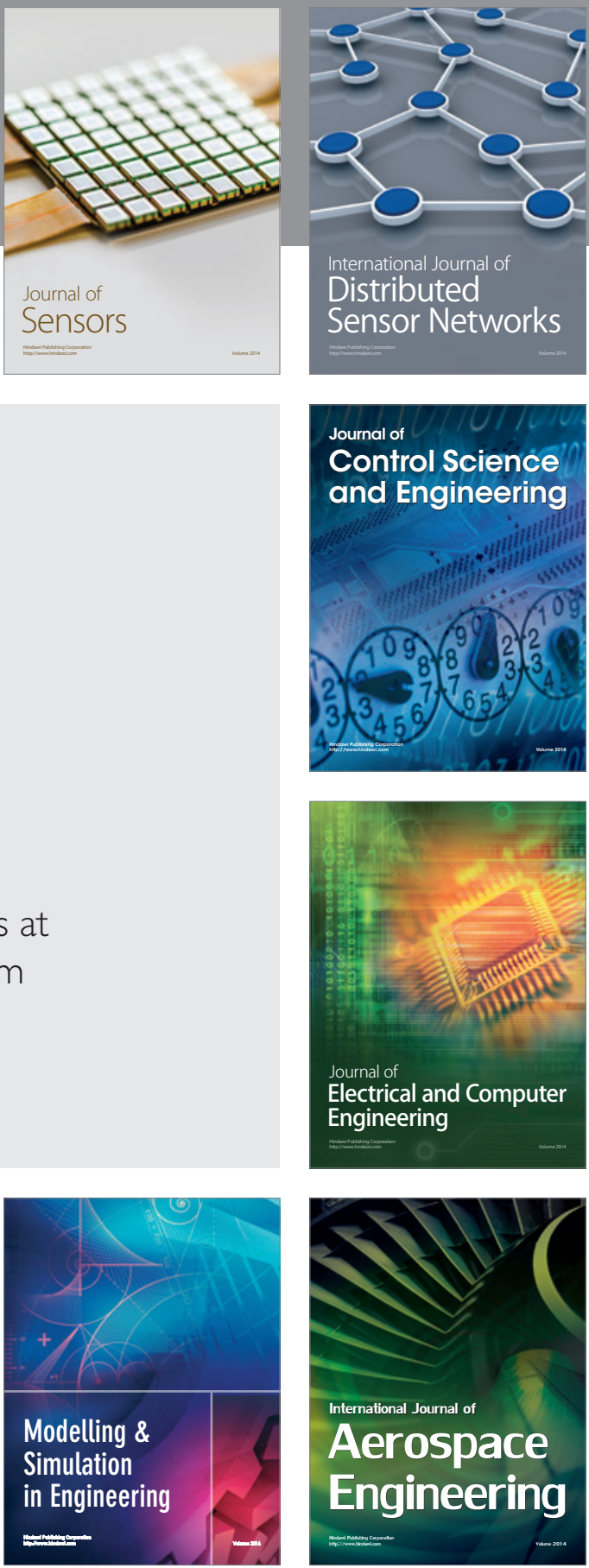

Journal of

Control Science

and Engineering
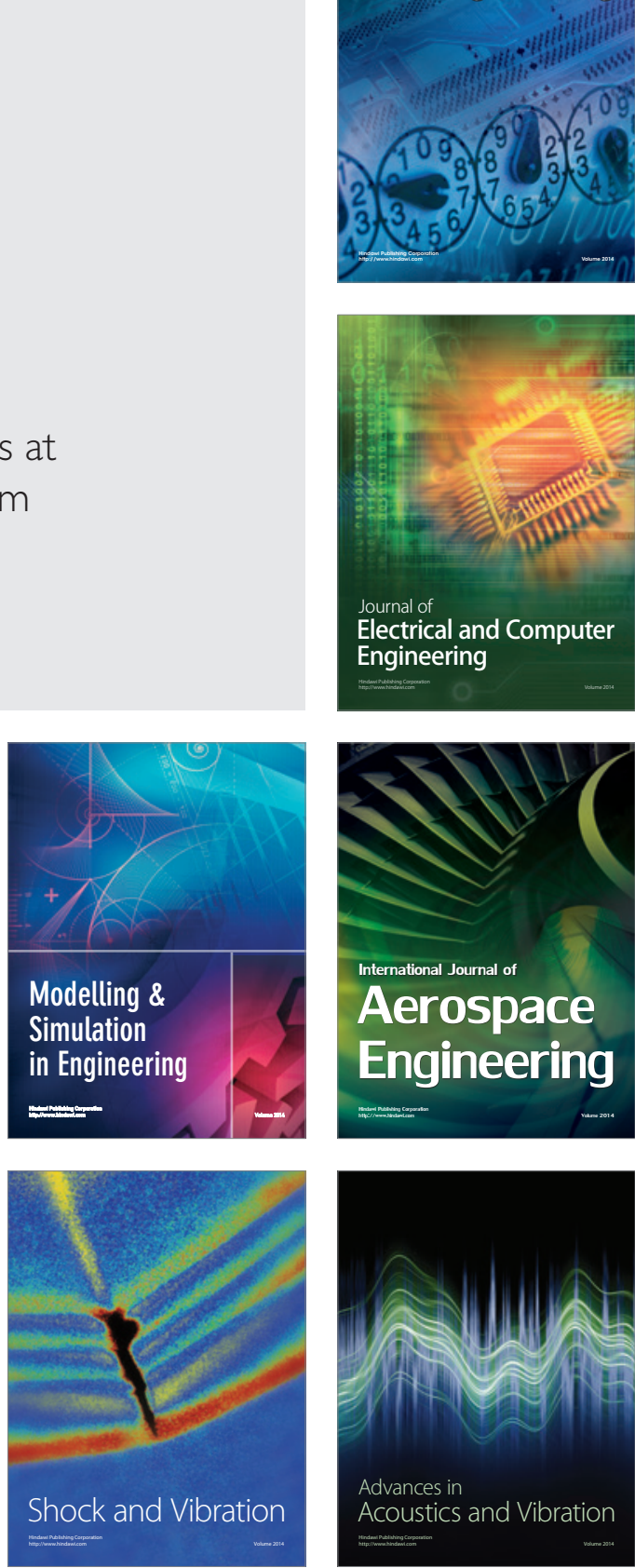